\title{
Fostering oral presentation skills by the timing of feedback: an exploratory study in virtual reality
}

\author{
Ilham Belboukhaddaoui ${ }^{\mathrm{a}}$, Stan van Ginkel ${ }^{\mathrm{b}}$ \\ ${ }^{a}$ University of Applied Sciences Utrecht, Ordina, the Netherlands, i.belboukhaddaoui@gmail.com \\ ${ }^{b}$ University of Applied Sciences Utrecht, Archimedes Institute, VR-Lab, the Netherlands, \\ stan.vanginkel@hu.nl
}

\begin{abstract}
Although scholars emphasised the essence of feedback delivered on virtual reality-based tasks, it remains unclear whether the acquisition of students' oral presentation skills can be enhanced by the timing of feedback. An exploratory study, recently conducted in a Dutch university, explores the potential differential impact of immediate versus delayed feedback within a virtual reality-based task, in which students present to a virtual audience and receive feedback generated by the computer on presentation behaviour. By making use of an experimental study design, the potential effects of immediate feedback are compared with a control condition of a virtual reality-based presentation task with delayed feedback directly provided after the presentation. Performance assessments, including validated rubrics for oral presentation skills, were used for data collection. The results demonstrated no differences between the impact of immediate and delayed feedback on students' presentation performance. However, significant differences in performance were traceable for students from differing study domains. As such, students following a technical study showed lower presentation scores in comparison to students from non-technical higher education curricula. More studies are needed to investigate comprehensive learning environments on students' presentation skills in virtual reality, since combining different forms of feedback could foster students' learning outcomes.
\end{abstract}

Keywords: feedback, higher education, oral presentation skills, virtual reality.

\section{Introduction}

Presenting is frequently considered as one of the core competencies for higher educated professionals (Campbell, Mothersbaugh, Brammer \& Taylor, 2001). This ability to speak in public is essential for career success and for effective participation in democratic societies (Smith \& Sodano, 2011). However, young professionals often fail to show effective presentation behaviour in working environments (Chan, 2011). Furthermore, these professionals experience this ability as one of the most prevalent fears in social situations (Smith \& Sodano, 2011). Within presentation research, public speaking can be defined as "a combination of knowledge, skills and attitudes needed to speak in public in order to inform, self-express, relate and to persuade" (De Grez, 2009, p. 5). Following this definition, the development of students' presentation behaviour can be fostered by any or all of these components referring to cognition, behaviour and attitude towards presenting (Van Ginkel, Gulikers, Biemans \& Mulder, 2015). Since this exploratory study focuses specifically on virtual reality, as an innovative technology, to improve students' presentation skills, it focuses solely on the presentation behaviour component.

A recently published systematic review study in Educational Research Review constructed a comprehensive set of educational design principles for developing oral presentation competence (Van Ginkel et al., 2015). The study demonstrated that three of the - in total - seven principles were directly referring to formative assessment strategies. While emphasising the essence of the type of feedback, peer assessment and self-assessment, it remains unclear whether innovative technologies can be valuable for delivering feedback messages during or after students' presentation rehearsals in virtual reality. Such technologies, as virtual reality, may impact students' presentation skills, since these technologies can imitate real-life situations in realistic educational settings (Merchant Goetz, Cifuentes, KeeneyKennicutt \& Davis, 2014). Moreover, virtual reality has the functionality to facilitate feedback to the presenter regarding presentation delivery aspects such as eye contact and use of voice. A recently conducted experiment showed that a virtual reality-based presentation task, to deliver delayed feedback on students' presentations, is as effective as a face-to-face presentation task accompanied with teacher feedback (Van Ginkel et al., 2019). Furthermore, another study suggested that immediate feedback during oral presentations in front of a virtual audience can be an effective feedback modality as well (Chollet et al., 2015; Tanveer, Lin \& Hoque, 2015). However, it remains unclear whether there is a 


\section{Fostering oral presentation skills by the timing of feedback: an explorative study on virtual reality \\ Belboukhaddaoui, van Ginkel}

potential differential impact between immediate versus delayed feedback within virtual reality-based tasks on developing students' presentation skills. Furthermore, it is questionable to what extent students' learning gains from practicing in virtual reality can be generalised to those in students with different characteristics (such as age or study domain). Therefore, the goal of this study is (1) to explore the potential differential impact between immediate versus delayed feedback on students' presentation skills in virtual reality and (2) to verify to what extent student characteristics might influence students' performance after presentation rehearsals in virtual reality.

From a scientific perspective, these research goals are relevant, since the potential differential impact between immediate and delayed feedback has not yet been researched by making use of virtual reality (Van Ginkel et al., 2019). Findings of such a study may further refine one of the crucial design principles relating to the 'type of feedback' within presentation research (Van Ginkel et al., 2015). From an educational practice perspective, the highlighted research focus is crucial, since many educators and teacher educators around the globe are aiming to develop effective presentation learning environments (Chan, 2011). However, especially in times when student numbers rise, while instructional times are diminishing, virtual reality-based tools might be an interesting alternative for time-consuming face-to-face teacher-student interaction. Within the discussion section of this paper, specific focus is directed to the potential application of virtual reality-based tools in teacher education institutions, since such technologies could (1) foster varying teacher competencies and (2) potentially change the role of teachers in the near future.

\section{Theoretical Framework}

After adopting virtual reality within the entrainment industries in the 1960 s, this innovative technology became more relevant for educational tasks since the technology improved, costs dropped and high-speed internet connections increased (Hawkins, 1995). Besides preparing pilots for their flying tasks, this virtual reality technology helped to explain complex concepts in physics to students at varying educational levels (Coller \& Shernoff, 2009). Recent metaanalyses on virtual reality showed that these technologies could have positive impacts on learning (e.g. Merchant et al., 2014).

With regard to presentation research, presenting in virtual reality reduces levels of speaking anxiety (e.g. Pertaub, Slater \& Barker, 2001), while other studies show that this technology can also facilitate students' development in presentation skills (e.g. Chollet et al., 2015). In line with this, Van Ginkel et al. (2019) revealed, by making use of an experimental study design, that students' development in presentations skill significantly increased by making use of virtual reality without a difference in comparison to a face-to-face task accompanied with teacher feedback. An argument for this finding relates to the fact that students highly appreciated the feedback they received after their presentation in virtual reality, because of its detailed and analytical character.

Another option is to make use of immediate feedback on presentation delivery aspects during speeches in front of virtual audiences (e.g. Chollet et al., 2015). Research on this topic showed that sparse feedback strategies were more positive in impact on oral presentation skills than continuous or no feedback at all (Tanveer et al., 2015). However, it remains unknown whether immediate feedback could be as effective as delayed feedback in which the presenter receives feedback after the presentation (Van Ginkel et al., 2019). Previous studies on the effectivity of immediate versus delayed feedback revealed that the literature is inconclusive at this point (e.g. DeLucenay, Conn \& Corigliano, 2017; Dihoff, Brosvic, Epstein \& Cook, 2004; Metcalfe, Kornell \& Finn, 2009).

In summary, it can be stated that (1) virtual reality can be an effective innovative tool for reducing speaking anxiety and developing students' presentations skills in realistic educational settings, (2) virtual reality-based tasks could generate both immediate and delayed feedback on students' presentation performances, (3) little is known about the potential differential impact of these feedback modalities within the context of virtual reality and (4) it remains unclear to what extent student characteristics might influence students' performances after rehearsing their presentations in virtual reality.

Concluding, the following hypothesis can be formulated for this study: 'A virtual reality-based presentation task with immediate feedback generated by the computer is as effective as a virtual reality-based presentation task with delayed feedback generated by the computer and explained in qualitative feedback messages'.

\section{Method}

\subsection{Participants}

In 2018, 30 undergraduate students enrolled in a two-hour presentation session provided within the Dutch higher education context. These students were selected based on their willingness to improve their presentation skills besides their regular curriculum. Of these 30 students, 17 were female and 13 were male. Furthermore, the average age of these students was 22 years, ranging from 18 years (the youngest participant) to 28 years (the oldest participant). All students followed a study program at the same university. However, their study domains differed between the participants from Social Work to Mechanical Engineering.

\subsection{Research design}




\section{Fostering oral presentation skills by the timing of feedback: an explorative study on virtual reality \\ Belboukhaddaoui, van Ginkel}

Before starting this experimental study, both students and researchers signed the informed consent form. Furthermore, the 30 students were randomly assigned over the following two conditions: (1) the virtual reality-based presentation task with immediate feedback ( $n$ 15) and (2) the virtual reality-based presentation task with delayed feedback (n 15).

Within the immediate feedback condition, students had to present five minutes in front of a virtual audience consisting of a classroom with students of their age (avatars). Therefore, these presenting students used a virtual reality glass and an additional headphone. During their presentations, the students received immediate feedback on presentation delivery aspects, such as eye contact and the use of voice. For example, if the presenter watched for more than five seconds to the slides, then an icon, projected in virtual reality, turned 'red' meaning that the student needed to make eye contact again with the virtual audience (see an example of immediate feedback in Fig. 1). Another example relates to speech rate. If the presenter spoke too fast, then an icon turned red with the message 'too fast', meaning that the student needed to speak a bit slower. The other condition focused on delayed feedback and consisted of a fiveminute presentation in front of a virtual audience and receiving feedback directly after the performance. As such, the presenter received feedback on presentation delivery aspects (the same as in the immediate feedback condition), which were registered by the computer system and explained in the form of a feedback message. An example of such a message is: 'Regarding the use of your voice, try to vary intonation during your introduction. This may help you to attract and hold your audience's attention'.

After the presentation performance in virtual reality, all participants from both conditions presented for five minutes face to face to a small group of peers comparable to the number of avatars in the virtual reality environment. Subsequently, all presentations were assessed by the first author of this study regarding presentation delivery aspects (e.g. eye contact and use of voice) comparable with the aspects traced by the virtual reality computer system. For assessing these aspects, the validated rubric oral presentation skills were adopted (Van Ginkel et al., 2017).

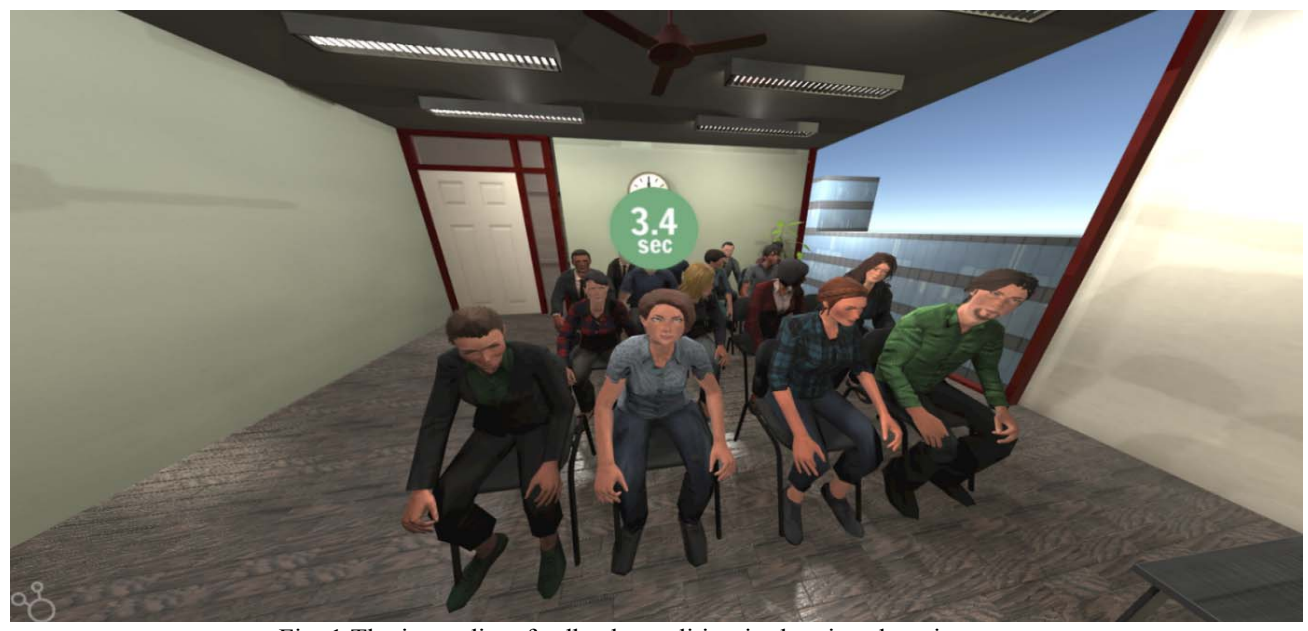

Fig. 1 The immediate feedback condition in the virtual environment

\subsection{Dependent variables and instruments}

Students' scores on presentation performance were measured based on the rubric 'oral presentation skills' (Van Ginkel et al., 2017). This instrument was previously validated by deducing educational design principles from the presentation literature (Van Ginkel et al., 2015) and by eliciting perceptions from presentation experts from varying domains and countries around the world (Van Ginkel et al., 2017). This rubric contained the four main criteria for effective presentations, including: (1) the content of the presentation, (2) the structure of the presentation, (3) interaction with the audience and (4) presentation delivery aspects (such as eye contact and use of voice). Since the virtual reality system could solely provide feedback on presentation delivery aspects, only the fourth component has been selected for the presentation assessment in this study. The subcriteria for presentation delivery (eye contact and use of voice) were written out in five performance levels. Each cell describes the behaviour shown at that specific level in a qualitative message (see Fig. 2 for an example of the subcriterion 'eye contact'). 


\begin{tabular}{|l|l|l|l|l|l|l|}
\hline & $\mathbf{( 1 0 )}$ & $\mathbf{( 8 )}$ & $\mathbf{( 6 )}$ & $\mathbf{- ( 2 )}$ & Score \\
\hline $\begin{array}{l}\text { Eye } \\
\text { contact }\end{array}$ & $\begin{array}{l}\text { The student has been } \\
\text { able to maintain eye } \\
\text { contact with the } \\
\text { audience continuously. }\end{array}$ & $\begin{array}{l}\text { The student has } \\
\text { been able to } \\
\text { maintain eye } \\
\text { contact with the } \\
\text { audience for } \\
\text { most of the time. }\end{array}$ & $\begin{array}{l}\text { The student has been } \\
\text { able to maintain eye } \\
\text { contact with the } \\
\text { audience on a regular } \\
\text { basis and only } \\
\text { sometimes he/she had } \\
\text { to look at his/her notes. }\end{array}$ & $\begin{array}{l}\text { The student has been } \\
\text { able to keep eye contact } \\
\text { with the audience } \\
\text { occasionally, because } \\
\text { he/she often had to look } \\
\text { at his/her notes. }\end{array}$ & $\begin{array}{l}\text { The student } \\
\text { mainly had a } \\
\text { look at } \\
\text { his/her } \\
\text { notes. }\end{array}$ \\
\hline
\end{tabular}

Fig. 2 An example of a subcriterion within the rubric oral presentation skills

\subsection{Data analyses}

Students' presentation performances were measured by one of the authors and an independent assessor. In order to determine the degree of consistency, the interrater reliability was calculated and revealed an acceptable score (Cohen's kappa 0.86). Furthermore, for each criterion (eye contact and use of voice), independent t-tests were adopted to verify potential differences in impact between the immediate and delayed feedback conditions. In addition, the same tests were used to investigate differences between the conditions regarding the overall performance of 'presentation delivery aspects' (eye contact and use of voice combined). Scores were calculated by taking the averages on each of the presentation criteria. Subsequently, other statistical analyses were used for determining the impact of student characteristics, such as study domain and age, on students' presentation performance. Therefore, a two-way ANOVA analysis was adopted to verify the impact of study domain (non-technical versus technical study program) on the aspect of presentation delivery. Finally, a linear regression analysis was executed to investigate whether students' presentation performance could be predicted by the age of the participant.

\section{Results}

First of all, outcomes focusing on the potential differential impact between immediate versus delayed feedback on students' presentation performance are described in this section. Furthermore, the impact of student characteristics, such as study domain and age, on presentation performance is presented in this section.

\subsection{Potential differences in impact between immediate versus delayed feedback}

For each subcriterion, such as eye contact and use of voice, is verified whether there was a differential impact between immediate and delayed feedback. Analyses revealed that there is no difference in impact between these two forms of feedback on the presentation delivery aspect 'eye contact' ( $t$ (28) 0.957, p 0.347). Furthermore, by adopting the same type of analysis, no differences were found in students' performance on 'use of voice' in those who received immediate or delayed feedback ( $\mathrm{t}(28)$ 0.000, $\mathrm{p}$ 1.000). See Table 1 for detailed characteristics. Finally, the potential differential impact between the conditions on the combined subcriteria (eye contact and use of voice) was calculated. This analysis showed that there was no difference between immediate and delayed feedback $(\mathrm{t}(28)$ 1.012, $\mathrm{p} 0.320)$. See Table 2 for more details.

\begin{tabular}{lll}
\hline & Immediate & Delayed \\
\hline Subcriteria & $M(\mathrm{SD})$ & $M(S D)$ \\
\hline Eye contact & $6.27(2.25)$ & $5.47(2.33)$ \\
\hline Use of voice & $5.33(1.45)$ & $5.33(1.45)$
\end{tabular}

Table 1. Scores on presentation delivery aspects 'eye contact' and 'use of voice' relating to the two feedback conditions 
Fostering oral presentation skills by the timing of feedback: an explorative study on virtual reality

Belboukhaddaoui, van Ginkel

\begin{tabular}{lll}
\hline & Immediate & Delayed \\
\hline Criterion & $M(\mathrm{SD})$ & $M(S D)$ \\
\hline Presentation delivery & $5.80(1.46)$ & $5.40(1.42)$
\end{tabular}

Table 2. Scores on presentation delivery aspects (overall) relating to the two feedback conditions

\subsection{The impact of student characteristics on presentation performance}

Regarding the potential impact of student characteristics on presentation performance, results revealed no differential impact of the factor age on students' presentation performance. However, another analysis showed a significant differential impact of the type of study domain (non-technical versus technical) on students' presentation skills (F (1, 30) 7.22, p 0.12). Students who followed a technical study program scored significantly lower on their face-to-face presentation performance after their rehearsal in virtual reality.

\section{Conclusions and discussion}

First of all, this study revealed no differences in impact between immediate and delayed feedback on students' presentation performance. Arguments for the comparability in effectivity of the two conditions can be deduced based on previous presentation research. In an earlier study, King, Young and Behnke (2000) revealed that immediate feedback was superior to influence aspects that are rather immediate (e.g. eye contact and use of voice), whereas delayed feedback can be effective for encouraging aspects of presentation skills that require more deliberate and effortful processing (e.g. adapting the length of a presentation or structure). Furthermore, Van Ginkel et al. (2019) emphasised that delayed feedback, directly provided after a presentation rehearsal in virtual reality, can be effective as well, because students appreciate this type of feedback regarding the detailed and analytical character. Considering the effectivity of both types, immediate and delayed feedback should be incorporated in effective presentation environments in higher education contexts, since a combination of both feedback modes could increase the quality of feedback messages (Van Ginkel, Gulikers, Biemans \& Mulder, 2017b). As a result, educational design principle five (Van Ginkel et al., 2015), regarding the type of feedback, could be further improved and optimised, which will further encourage the development of students' presentation skills.

Another result from this study relates to the fact that more insight has been generated into the potential impact of student characteristics on presentation performance after rehearsals in virtual reality. Significant differences in student characteristics were found for the factor 'study domain', as students from non-technical domains outperformed students following technical study programs. This difference in performance might refer to technical curricula focussing more on teaching domain-specific skills instead of integrating soft skills, such as presentation competencies, in their educational programs. However, several recent studies in presentation research describe developing presentation skills in technical curricula (e.g. Mitrovic, Gostomski, Herritsch \& Dimitrova, 2017; Mohamed, Asmawi, Hamid \& Mustafa, 2015). Another argument for the lack of presentation skills amongst technical students might relate to the idea that technical students naturally possess fewer communication competencies in comparison to students from non-technical curricula. Since there is a lack of evidence in presentation literature regarding this issue, more research is needed towards (1) the integration of presentation environments in technical curricula and (2) the role of students' traits, prior competencies and perceptions towards presenting in relation to presentation performances (see also Van Ginkel et al., 2015).

Several limitations remain that are important to keep in mind when interpreting the results of this study. First, the small sample size should be emphasised as a limitation. Although previous studies demonstrated the value of experimental studies with limited sample sizes (e.g. Biemans \& Simons, 1996; Van Ginkel et al., 2019), follow-up studies should increase the number of participants in order to strengthen the power of the study. Second, measuring presentation delivery, as a crucial component of presentation skills, was restricted to only eye contact and use of voice. However, presentation delivery aspects also contain 'posture and gestures' (Van Ginkel, Gulikers, Biemans \& Mulder, 2017a). Therefore, virtual reality technology should be further developed in such a way that it can generate feedback on this presentation delivery aspect as well. As a consequence, incorporating other relevant subcriteria of presentation delivery will automatically increase the validity of this study. Third, this exploratory study can be defined as an experimental study conducted within a laboratory setting that focuses on manipulating design principle five regarding the type of feedback (see Van Ginkel et al., 2015). However, previous studies revealed that - to effectively develop students' presentation skills - learning environments should incorporate all seven educational design principles (Van Ginkel et al., 2017a). A follow-up experiment conducted in a realistic presentation course based on this comprehensive set of principles could further optimise the ecological validity of such a study.

Taking these limitations into account, future research should focus on repeating this experimental study amongst a larger population. Furthermore, other cohorts of students should be selected, since it is questionable to what extent the findings of this study can be generalised to students in other educational contexts, such as primary and secondary 


\section{Fostering oral presentation skills by the timing of feedback: an explorative study on virtual reality \\ Belboukhaddaoui, van Ginkel}

education. In addition, recent developments in technology show that virtual reality applications are designed, including instruction, learning activities and assessment strategies (Van Ginkel et al., 2015), in which students can develop their presentation performances at any time and any place. The implementation of such comprehensive virtual learning environments could further support (1) the development of personalised learning and (2) optimising the role of selfassessment tasks in presentation education (Van Ginkel et al., 2017a).

Finally, integrating feedback modalities in virtual environments for presenting has several implications for educational practice. Adopting virtual reality in higher education fostering communication skills requires training of students, teachers, teacher educators and tutors before entering formative assessment processes (Van Ginkel et al., 2017). Besides applying virtual reality to foster presentation skills, other teacher competencies (e.g. classroom management and didactical skills) can be developed as well when developments in artificial intelligence increase, since certain communication competencies (besides presenting) imply more interaction and as a result require more complex computer systems. Furthermore, some learning environment characteristics, such as providing immediate or delayed feedback, might replace the role of the teacher at this point. Nevertheless, this statement challenges teachers, teacher educators and curriculum designers to effectively redevelop existing curricula in the higher education context. As a consequence, professional development of teachers should pay more attention to roles as 'educational designers' and 'coaching regarding personal learning objectives' rather than providing instruction or feedback as the only feedback source (besides peer feedback) in presentation curricula. Taking these practical implications into consideration, these activities require investments in terms of time and financial resources and should, therefore, directly relate to the strategic policy of teacher education institutions within the higher education context.

\section{References}

Biemans, H. J., \& Simons, P. R. J. (1996). CONTACT-2: A computer-assisted instructional strategy for promoting conceptual change. Instructional Science, 24(2), 157-176. https://doi.org/10.1007/BF00120487

Campbell, K. S., Mothersbaugh, D. L., Brammer, C., \& Taylor, T. (2001). Peer versus self-assessment of oral business presentation performance. Business Communication Quarterly, 64(3), $23-42$. https://doi.org/10.1177/108056990106400303

Chan, V. (2011). Teaching oral communication in undergraduate science: Are we doing enough and doing it right? Journal Of Learning Design, 4(3), 71-79. doi:10.5204/jld.v4i3.82

Chollet, M., Wörtwein, T., Morency, L. P., Shapiro, A., \& Scherer, S. (2015). Exploring feedback strategies to improve public speaking: an interactive virtual audience framework. In Proceedings of the 2015 ACM International Joint Conference on Pervasive and Ubiquitous Computing (pp. 1143-1154). ACM. doi: 10.1145/2750858.2806060

Coller, B. D., \& Shernoff, D. J. (2009). Video game-based education in mechanical engineering: a look at student engagement. International of Engineering Education, 25, 308-317. doi: 0949-149X/91

De Grez, L. (2009). Optimizing the instructional environment to learn presentation skills. Dissertation: Universiteit Gent.

DeLucenay, A. J., Conn, K. M., \& Corigliano, A. (2017). An evaluation of the impact of immediate compared to delayed feedback on the development of counselling skills in pharmacy students. Pharmacy Education, 17(1), 322328. http://pharmacyeducation.co.uk/pharmacyeducation/article/viewFile/480/447

Dihoff, R. E., Brosvic, G. M., Epstein, M. L., \& Cook, M. J. (2004). Provision of feedback during preparation for academic testing: Learning is enhanced by immediate but not delayed feedback. The Psychological Record, 54(2), 207. https://doi.org/10.1007/BF03395471

Hawkins, D. G. (1995). Virtual reality and passive simulators: the future of fun. In F. Biocca \& M. R. Levy (Ed.), Communication in the age of virtual reality (pp. 159-189). Hillsdale, NJ: Lawrence Erlbaum.

King, P., Young, M., \& Behnke, R. (2000). Public speaking performance improvement as a function of information processing in immediate and delayed feedback interventions. Communication Education, 49(4), $365-374$. https://doi.org/10.1080/03634520009379224

Merchant, Z., Goetz, E. T., Cifuentes, L., Keeney-Kennicutt, W., \& Davis, T. J. (2014). Effectiveness of virtual realitybased instruction on students' learning outcomes in K-12 and higher education: A meta-analysis. Computers \& Education, 70, 29-40. https://doi.org/10.1016/j.compedu.2013.07.033

Metcalfe, J., Kornell, N., \& Finn, B. (2009). Delayed versus immediate feedback in children's and adults' vocabulary learning. Memory \& Cognition, 37(8), 1077-1087. doi:10.3758/MC.37.8.1077

Mitrovic, A., Gostomski, P., Herritsch, A., \& Dimitrova, V. (2017). Improving presentation skills of first-year engineering students using active video watching. In 28th Annual Conference of the Australasian Association for Engineering Education, 809

Mohamed, A. A., Asmawi, A., Hamid, M. R. A., \& Mustafa, Z. B. (2015). Descriptive analysis of context evaluation instrument for technical oral presentation skills evaluation: A case study in English technical communication course. AIP Conference Proceedings, 1643(1), 536-540.

Pertaub, D-P., Slater, M., \& Barker, C. (2001). An experiment on fear of public speaking in virtual reality. In J. D. Westwood, H M. Hoffman, G. T. Mogel \& D. Stredney (Eds.) Medicine meets virtual reality (pp. 372-378). IOS 
Press.

https://www.researchgate.net/profile/Mel_Slater/publication/12017692_An_experiment_on_fear_of_public_speakin g_in_virtual_reality/links/00b495219d7573d4fa000000.pdf

Smith, C. M., \& Sodano, T. M. (2011). Integrating lecture capture as a teaching strategy to improve student presentation skills through self-assessment. Active Learning in Higher Education, 12(3), 151-162. https://doi.org/10.1177/1469787411415082

Tanveer, M. I., Lin, E., \& Hoque, M. E. (2015). Rhema: A real-time in-situ intelligent interface to help people with public speaking. In Proceedings of the 20th International Conference on Intelligent User Interfaces (pp. 286-295). ACM. doi: 10.1145/2678025.2701386

Van Ginkel, S., Gulikers, J., Biemans, H., \& Mulder, M. (2015). Towards a set of design principles for developing oral presentation competence: A synthesis of research in higher education. Educational Research Review, 14, 62-80. doi:10.1016/j.edurev.2015.02.002

Van Ginkel, S., Gulikers, J., Biemans, H., \& Mulder, M. (2017a). The impact of the feedback source on developing oral presentation competence. Studies in Higher Education, 42(9), 1671-1685. doi:10.1080/03075079.2015.1117064

Van Ginkel, S., Gulikers, J., Biemans, H., \& Mulder, M. (2017b). Fostering oral presentation performance: does the quality of feedback differ when provided by the teacher, peers or peers guided by tutor? Assessment and Evaluation in Higher Education, 42(6), 953-966. doi: 10.1080/02602938.2016.1212984

Van Ginkel, S., Gulikers, J., Biemans, H., Noroozi, O., Roozen, M., Bos, T., Van Tilborg, R., Van Halteren, M., \& Mulder, M. (2019). Fostering oral presentation competence through a virtual reality-based task for delivering feedback. Computers \& Education, 134, 78-97. https://doi.org/10.1016/j.compedu.2019.02.006

Van Ginkel, S., Laurentzen, R., Mulder, M., Mononen, A., Kyttä, J., \& Kortelainen, M. J. (2017). Assessing oral presentation performance: designing a rubric and testing its validity with an expert group. Journal of Applied Research in Higher Education, 9(3), 474-486. https://doi.org/10.1108/JARHE-02-2016-0012 